\title{
Speaking with Frankenstein
}

\section{Jayne Lewis $^{1}$ (D) Johanna Shapiro ${ }^{2}$}

Published online: 21 August 2020

(C) Springer Science+Business Media, LLC, part of Springer Nature 2020

\begin{abstract}
This collaborative essay experimentally applies the insights of Mary Shelley's 1818 gothic fantasy Frankenstein to clinical interactions between present-day physicians and the patients they, akin to Shelley's human protagonist, so often seem to bring (back) to life. Because that process is frequently fraught with unspoken elements of ambivalence, disappointment, frustration, and failure, we find in Shelley's speculative fiction less a cautionary tale of overreach than a dynamic parable of the role that the unspoken, the invisible, and the unknown might play in contemporary physician/patient relationships. Playing with that parable, we consider its relevance to four often unacknowledged dynamics that shape physician/patient interaction: commitment to a false binary of life and death; the tyranny of normative aesthetics; shared negative affect; and the ethics of care and care-denial. To "speak with Frankenstein" is, we show, to make space for the otherwise unspeakable. The result is a more complete model of narrative medicine that accommodates to its ideal of open communication and full attention the persistence of what cannot be said, seen, or known-only imagined and approximated.
\end{abstract}

Keywords Medical aesthetics · Narrative medicine - Gothic fiction · Medical ethics · Affect theory

\section{Introduction}

Is there anything left to say about Frankenstein? Probably not, says a flood of reassessment on the occasion of the book's two-hundredth birthday in 2018. Yet in itself that flood tells us that Mary Shelley's iconic novel is still very much here to be spoken with, at once a revelatory interlocutor in its own right and a versatile facilitator of other conversations. As a professor of literature and a professor of medicine, we are especially interested in what it might mean to "speak with" Victor Frankenstein and his Creature because this process can provide creative insight into the relationships that develop between modern-day physicians and the patients

Jayne Lewis

jelewis@uci.edu

1 Department of English, University of California, Irvine 92697, USA

2 School of Medicine, University of California, Irvine 92697, USA 
whom they so often, in a sense, bring (back) to life. Such relationships are themselves signified by verbal exchanges between physicians and patients - by the ways in which they speak or do not speak with one another. Here, however, we speculate as to how imaginative dialogue with a work of literary fiction that is itself grounded in speculation might illuminate such exchanges, thereby fostering previously unthinkable and indeed unspeakable forms of mutual understanding.

What do we mean by speaking with? How does it differ from speaking about? In the clinical setting, the distinction between speaking with and speaking about is easily grasped, especially when we map it onto the work of the medical sociologist Arthur Frank, who wrote perceptively that "thinking about" is an exclusively analytic, cognitive function reflecting the way in which physicians are trained to proceed logically and systematically through differential diagnosis. By contrast, to "think with" another is to enter into that person's world feelingly as well as intellectually (Frank 2013; Morris 2001). This modification does not dispute the merit of cogent logic. But it does stress respect for the patient. And insofar as respectful, feeling entry into another's world is made possible through language, it also entails close listening to spoken words in the scene of clinical encounter - to what is literally said, by patients about patients, on the examining table or in the hospital bed. Those words might or might not cohere into a complete story. And if they do, that story could oppose the one that the physician might wish to tell. "Thinking with" is thus an act of empathetic imagination entwined with the real-world process of "speaking with."

When it comes to engaging a work of literature, the concept of "speaking with" is less easily grasped, more metaphorical. Doctors literally speak with patients, but readers can only figuratively speak with novels. Nonetheless, a robust body of work in narrative medicine fully embraces literature's resources for shaping and interpreting the speech acts that both organize and represent clinical relationship. Perhaps most influentially, Rita Charon has shown how sterile clinical practice might regenerate when it draws on a deeply literary repertoire of principles - intersubjectivity, relationality, personhood and embodiment, action toward justice, and creativity - and skills such as attention, representation, and affiliation (Charon 2006, xi). Charon plots these principles and skills onto a triangle whose points are doctor, patient, and literary text (Charon et al. 2016).

While nuanced and transformative, this approach does not exhaust the range of possible relationships that readers might form with narrative fiction. Alternatives are most visible with works that break the modern novel's mimetic contract with reality and instead ground themselves in fantasy, speculation, and non-resemblance to a seemingly recognizable world. Such relevant subgenres as gothic literature, science fiction, and romance are all literary forms that Frankenstein helped to birth at a defining moment in the histories of both fiction and medicine. We sift these genres from the larger category of narrative per se because they do more than invite readerly interpretation, identification, and even imitation. They also activate the experimental imagination and animate a spirit of open-ended play. Just as valuably, they can ground Susan Sontag's notion of illness as "the night-side of life" (Sontag 1977, 3). Because they stimulate readerly disaffection, disaffiliation, and even incomprehension, such texts provide an opportunity to rehearse a range of probable and improbable responses to lived experience.

When we picture more than one reader playing, sometimes recklessly, with a work of narrative fiction's imaginative possibilities, we arrive at the sense of "speaking with" that we develop in this paper. More than narrating, interpreting, and responding, we understand "speaking with" as an intersubjective, associative, and notional approach to close reading that 
incorporates distance and disappointment as well as recognition and rehabilitation, unresolved fear as well as pragmatic hope. To shift our attention from the "narrative" aspect of "narrative fiction" to its "fictive" dimension is to move from "what is" to "what if"-from what is said and done to what by definition doesn't happen and to the question of what it might mean were it to do so. Such a change of perspective revises some of narrative medicine's desiderata - e.g., honest communication, empathy-without ruling out the possibility of their achievement. For example, with respect to Charon's categories, speaking with Frankenstein in our sense redirects the undisputed value of attention; instead of perfect presence to an Other, attention comes to imply also waiting and suspense, a provisional and contingent relationality. Similarly, we consider the role that unrealized outcomes play in present-time embodiments. Such considerations are ultimately ethical ones. What we do not know but can imagine about people and their predicaments - always remaining aware that we are imagining them, and that they exceed our projections on and through them-still allows us to treat them with respect and caring. But here respect and caring retain an element of interpretive liberty, yielding acts of affiliation and recognition based not just on perceived similarity but also on the acceptance of distance, disappointment, and difference.

We find that Shelley anticipated such possibilities when she staged a series of broken yet still promising interactions between her protagonists, the failed medical student Victor Frankenstein and the Creature into whose crowd-sourced, incoherent body-once a "lifeless thing"-Victor "infuse[s] a spark of being" (Shelley 1993, 38). An impressively long-lived, polyvocal freak of fiction, Frankenstein can help us imagine alternative outcomes for the lifesaving yet deeply conflicted, often incoherent and inscrutable relationship that can develop between even the best-intentioned doctors and most compliant patients. The former often unwittingly stumble into some of Victor's errors with respect to his Creature; the latter, as a result of internalizing physician and societal fearful attitudes toward illness, can come to identify with the monster. Hence deeper dynamics of death denial, revulsion, repudiation, recognition-seeking, and revolt go largely unspoken.

A robust subgenre of critical studies already views Frankenstein through the lenses of regenerative and prosthetic medicine (Webster 2018), genetic engineering (Rollin 2004), reproductive technology (Savulescu and Harris 2004), disability (Bradshaw 2019; Stoddard Holmes 2018), the history and psychology of epidemics (Quick and Fryer 2018), and even representations of physicians, thanks especially to the many twentieth-century film adaptations that literally put "Dr. Frankenstein" in scrubs. Despite so many medicalized interpretations of Frankenstein, Jeffrey Johnson's contribution to the journal Literature and Medicine's recent "themed issue" on Frankenstein usefully reminds us that "Victor is in no sense a medical doctor" (Johnson 2018, 287). Johnson, however, overlooks the sixth "sense" of the imagination - precisely the "powerful engine," to quote Shelley herself, that Frankenstein's medicalizing readers have brought to bear upon the novel. As Anthony Appiah has recently explored, this "powerful engine" is a resource that allows us to speak, together, "as if"; we may best share, test, and revise our ideals when we speculate about "what a world would be like in which something that is not, in fact, true were true" (Appiah 2017, 171).

In treating Victor "as if" he were the medical doctor he is training to become and the Creature his perceived difficult patient, we do not place Shelley's novel in a cultural history of medicine that it might be seen to allegorize. Nor do we insist on an analogy between patient and Creature; if anything, we are attuned to the places where analogy breaks down. For example, the living patient will have access to a personal history - a history of one person that has unfolded over unbroken time. By contrast, Shelley's Creature can access his own 
miscellaneous history — and imagine himself as a unified character within that history — only by reading his creator's lab journals or by imagining himself into the plots of such works of literature as Milton's Paradise Lost. The similarities that might persist within this difference between the Creature and the living patient are all the more significant, however: a patient's socalled "intake history" may not at all fit their lived history, any more than Victor's journals tell the truth about who or what the Creature has been. Still, such parallels do not add up to any more of a likeness between patient and creature than the Creature himself might bear to his creator, who has after all donated none of his own biological material to his monstrous progeny. Such distances are themselves vital to any perception of commonality. Physicians who appreciate this can potentially access their patients' voices through more humble acts of listening to the gaps in what they say. Patients who appreciate it might hear what their physicians are trying to say, not just what they are saying.

In dialogue with Shelley's own fictional design, then, we experiment, even play, with the "as ifs" that this prototypic gothic novel brings to light. Speaking with Frankenstein, and with each other, "as if" the book were about the clinical relationship makes it possible for us to consider - and, more important, to speak about - the often competing human conditions of physicians and the patients. If we stop short of recommending that medical schools add Frankenstein to the first-year curriculum, or of proposing that waiting rooms display a copy of the book alongside last month's issue of Family Circle, we nonetheless model one application for Shelley's novel. We strive to realize its commitment not just to what isn't quite seen but to language's unique capacity to bring its speakers closer to what has been invisible, even as it acknowledges what must remain so.

\section{Speaking of Frankenstein..}

Notwithstanding the early adaptation to the stage that catapulted it into visual culture, we should remember that Frankenstein was generated in and through language. The novel's legendary origin was a lurid nightmare, Mary Shelley's "acute mental vision" of the "hideous phantasm of a man stretched out, and then, on the working of some powerful engine, show[ing] signs of life, and stirring with an uneasy, half-vital motion" (196). But that "vision" itself was sparked by earlier "conversations" about the "principle of life" that unfolded between two established poets, Shelley's fiancé, Percy Bysshe Shelley, and his notorious chum, Lord Byron. Mary Shelley pronounced herself "a devout but nearly silent listener" to those "conversations" (195), but the story she then penned uneasily explored (through language) the "principle of life" under discussion, transforming a nineteen-year-old girl's silence into participation.

Another, more fabled origin of the book is a ghost story writing contest between the Shelleys, the club-footed Byron, and the latter's personal physician, John Polidori. In the wake of Michel Foucault's epochal Birth of the Clinic (Foucault 1973), with its relentless focus on the wakeful "clinical gaze," it is easy to forget that medical practice also involves the exchange of language. Frankenstein presents such exchange as the foundation of interpersonal reality and insight. For all its vaunted investigation of the torments of the isolated romantic psyche, the novel is organized in concentric circles devoted to the communication of what cannot otherwise be seen. Letters sent by Robert Walton, a frustrated polar explorer, to his sister back in London enclose a record of Walton's long conversation with Victor Frankenstein, whom Walton has rescued, half-dead, from the ice floes, and is nursing aboard his own ship. That record in turn 
transmits Victor Frankenstein's own first-person story. As told to Walton, this story centers on the hearing that Victor reluctantly gives to the monster he made but cannot bear to look upon.

These three givers, receivers, and, often, withholders of bodily care too often speak past one another, establishing an essential medium of exchange - language - as an unreliable one. The Creature's moving narrative is a plea for recognition. It expresses his thwarted hopes to be seen and heard by Frankenstein himself and his longing for a partner who might share his loneliness and isolation. Yet the Creature is also a proficient rhetorician who manipulates Victor into doing what he wants, possibly lying about his own motives so as to realize ultimately destructive longings. Similar contradictions and uncertainties haunt Victor's no less moving - and no less manipulative and self-serving - story of isolation and heroic aspiration as told to the explorer Walton. Walton's own idealization of and identification with Victor prevent him from hearing the deeper truths of hubris and guilt that Victor inadvertently tells.

Walton's own words, however, also show that he is able to break out of narrative monologue to work with and beyond Victor's own words. This movement potentially modifies Walton's experience of both Frankenstein and his unnamed creature. Thus at the end of the book, having at last seen Frankenstein's monster face-to-face - "never did I behold a vision so horrible as his face, of such loathsome, yet appalling hideousness" (187)—Walton seems to grasp that he is seeing his own unsightly "vision," not necessarily the Creature's true visage. So he lets the body that bears that visage go free. Instead of rejecting outright the hypothesis of the Creature's essential humanity, he literally opens the end of an otherwise closed narrative. His action, couched in a non-action, authorizes, liberates, and indeed inspires any reader to 'open' other narratives, both lived and imagined, toward possibilities that could not have been imagined before. The Creature himself will live on after the story has ended. Infinitely many new versions of that story will be produced, bringing Frankenstein as a cultural phenomenon together with what happens inside Shelley's originary fiction.

Frankenstein seeks a versatile language that can cross difficult boundaries between persons while also acknowledging those boundaries' intransigence - a language that can also travel between what if and what is. This is often a language of inexact analogy, figurative in the unconventional ways exemplified by Walton's slippery "vision so horrible as his face." Speaking with that language, and also in dialogue with Shelley's open-ended gothic plot and unresolved characters, we are able to pose four questions that speak to present-day relationships between physicians and patients: 1) In what sense does a physician bring a patient (back) to (their) life? 2) How do aesthetic categories - standards of perfection and beauty, expectations and perceptions of likeness and difference - structure the desires of and ultimately the relationships between physicians and their patients? 3) What parallel feelings arise when these categories of difference are violated? 4) What are the physician's ongoing responsibilities to a creation that falls short of expectations and defies medical expertise; and are these responsibilities in fact shared between physician and patient?

Certain assumptions underpin these questions. First, while a patient might be construed — or construe themselves - in any number of ways (as a client or employer, say, as a subject or an object), they are also as subjects or objects of illness in effect co-created with the physician, often through literal conversations. Second, the resulting creation does not necessarily conform either to a physician's original vision or to the patient's image of perfection. Third, when those visions and images are spoiled, specific feelings arise. Prominent among them may be shame, anger, and despair on the patient's part and disgust and anxiety, even fear, on that of the physician. Finally, if abandonment (disappearance) and blame are among a physician's ethical choices in the face of a 'failed' treatment, those of the patient might range from compliance to 
self-blame, deception, ironic mimicry, and outright revolt. As with the physician, the patient's actions might also include disappearance from the therapeutic scene. Vanishing, we suppose, may be of value to the patient while remaining incomprehensible both to the doctor and to the society whose interests the doctor represents.

\section{In what sense does a physician bring a patient (back) to (their) life?}

Shelley's frequently forgotten subtitle is The Modern Prometheus. In a rather stale reprise of Promethean overreach, Victor Frankenstein literally creates life. Such an act is more grandiose than, but akin to, saving a patient's life (cured of cancer), deepening or expanding their quality of life (prosthetic surgery), or even literally bringing a patient back to life (resuscitation). This miraculous, possibly hubristic, dimension of medicine is often enshrined as the "ideal" of medicine, an aspirational goal for all physicians, despite the fact that increasingly medicine, especially outpatient medicine, is concerned with the management of chronic disease (Wade and Halligan 2017).

What does "bring to life" mean in the context of contemporary medical practice? Of course, there are the life-saving or life-enhancing heroics described above. But there is also a larger sense in which most patients are brought (back) to life if we acknowledge that, for many if not most, "life" and "story" are synonymous. At this more symbolic level, patients seek medical attention because of narrative disruption (Frank 2000; Williams 2000; Locock and Ziebland 2015). Pain, dysfunction, and other epiphenomena of illness have impaired their life-stories, or in the case of a chronic disease such as diabetes or cancer, foreshadow future narrative dislocation. Such patients seek to have a continuous narrative restored.

The hoped-for goal of restitution implies a reconstruction of and return to the patient's previous narrative. This is what the patient wants, envisions, and even expects first and foremost. It is what the doctor, equally committed, attempts to deliver. As Frank points out, the restitution narrative in medicine does apply sometimes in some situations - the patient breaks her leg skiing, the leg is set and casted, and six weeks later the patient returns to the slopes, her pre-fracture narrative restored (Frank 2013). But in many instances, while medicine does its best to return the patient to the pre-illness state, the results may be imperfect. There may be lingering pain, disability, fatigue, limits in function, increased risks of other medical conditions as a consequence of treatment, or recurrence of disease. Deeper, unacknowledged emotional changes may persist despite surface restoration. Thus the question becomes, how might doctors speak with their patients about such imperfections and vulnerabilities?

As it happens, modern medical bringing-to-life at once recapitulates and reinforces the personal image that Victor Frankenstein cultivates when he famously aims to "break through" the "ideal bounds" of "life and death" and thereby "pour a torrent of life into our dark world" (36). In this heroic aspiration, Victor tenders a debatable prototype for the physician as savior and even demigod, an outdated but still alluring model even today (Nassir 2008). Speaking with his multivalent example lets us see that Victor himself might be relying on antiquated paradigms, from creaky Promethean myths to alchemical formulas awkwardly revived in a modern "laboratory" crammed with "machines." These fixed forms actually seem to limit his imagination and with it his powers to create a truly new, truly dynamic, and truly adaptive life.

Victor's raw materials hail from the world of corruption, death, and decay. Filched from "vaults and charnel houses," abattoirs and dissecting theatres, the discrete body parts that he collects have only the purely animal responsibility to move. They are physical objects without content or meaning in themselves except as passive recipients of the personal glory the life- 
bringing physician would project onto them. If it is to come fully to human life, the body they make up must possess more than formal coherence; it must do more than simply resemble a standard-issue human frame. Also necessary may be some acknowledgment of intractable physicality. Such acknowledgment could yield a truth that Victor himself can express only indirectly: death is at once the living body's opposite and integral to its identity.

That truth is embodied in the ungraspable "being" that Victor brings to life. From the moment that "the dull yellow eye of the creature open[s]," that creature manifests marks of the very sickness, debility, and mortality from which Victor would liberate the human "being": "yellow skin," "watery eyes, that seemed almost of the same colour as the dun white sockets in which they were set," the jerky movement that film monster Boris Karloff would copy from polio patients (Codr 2014, 179), "hard" breathing while "a convulsive motion agitate[s] its limbs" (39). Illness (tremors, jaundice, eye disease) is indelible, the body's bent toward death and disability uncorrectable. Not unlike the possibility of relapse, unsuccessful treatment, or an otherwise imperfect cure - and like recognition of the uncertainty that attends any therapeutic intercessions, from cataract surgery to chemotherapy - these reminders of fallibility and mortality demand to be incorporated into the new life that Victor has created. There is no returning to previous whole bodies or to a founding image of perfection.

Significantly, Shelley leaves it to her invisible interlocutor, the reader, to sense the power and persistence of such ideals and visions, as well as to confront their limits in bodily reality. To speak with Frankenstein - to imagine with its medically marked characters from inside its own vital but undecided medium of language - is to open up new possibilities for acknowledgment, including acknowledgment of what human life truly is, means, and can be. Such acknowledgment might give patient and physician, creature and creator, an equal shot, through speaking with each other, at establishing such meaning, and of generating no less meaningful ways of living it out in a co-created future. While the essence of medical practice is bringing/ restoring to life, this act can be questioned, debated, and potentially redefined, so that "life" and the stories we tell about our own lives incorporate the realities of incoherence, incompleteness, and death.

\section{Aesthetics, likeness, and difference: "I had selected his features as beautiful"}

How do aesthetic categories - culturally conditioned standards of perfection, conformity, and beauty - shape the relationship between physicians and their patients? Beauty matters in modern medicine. We speak of "the picture of health" without questioning the metaphor. Even when plastic surgery is not a factor, medicine retains an aesthetic bias, even relying on visual technologies of imaging. It prefers beauty over ugliness, form over formlessness, conformity over nonconformity (Macnaughton 2015, 175). Victor Frankenstein prefers all of these qualities as well, deferring to the ideals that back them. He had, he tells Walton, "selected [the Creature's] features as beautiful." Likewise, it is the Creature's offense against the same ideals ("Beautiful! Great God!") that seems to motivate-even legitimate-Victor's subsequent treatment of the "Being" he has brought to unsightly life. That being is, simply, "hideous," the adjective that Victor most often applies to him, despite some of the beautiful "features" he retains, such as "flowing" hair and "straight white teeth" (39).

Victor's attachment to beauty, his horror at what falls short of it, is linked to his inability to control the results of his artistic efforts. This leads us to imagine that medical aesthetics too are ways of imposing at least the illusion of order and control. Like Frankenstein's creature, some patients inadvertently puncture that illusion. What then is to be done? Victor's solution is not 
admirable, though we might secretly sympathize with it. He literally refuses to see his creature, even as he seems riveted by its physical appearance, bolting instantly from his "workshop of filthy creation" the second it comes to life. When the creation in question turns up at his bedside in a parodic reversal of a house call, Victor is too sickened by the sight to see much of anything: "a cold dew covered my forehead, my teeth chattered; and every limb became convulsed." The Creature, for his part, "fixes his eyes" ("if eyes they may be called") on Victor's. But the monster does not only look; he also "mutter[s] some inarticulate sounds, while a grin wrinkled his cheeks. He might have spoken, but I did not hear; one hand was stretched out, seemingly to detain me, but I escaped, and rushed down stairs" (39-40). Inseparable from his attachment to abstract ideals, Victor's reliance on the evidence of his eyes makes it impossible to know the reconstituted life in front of him as itself. Yet the Creature's attempt at contact potentially revises his relationship to Victor, positing an alternative vocabulary that accommodates the unknown as well as the known, the imperfect and invisible, what might be as well as what only apparently is.

Why does Victor refuse to learn this vocabulary? His flight strikes us as a reaction to the Creature's grotesque deviance from preconceptions of beauty, "normalcy," and similarity. From this point of view, Victor flees radical difference: the Creature's difference from an aesthetic ideal, from expectation, and from Victor's own "attractive and amiable" appearance, as appreciated by Walton (15). In this Frankenstein copies his own society, whose individual members likewise hysterically recoil from the Creature's visual difference and seek to drive him out. Indeed, the only individuals who do not repudiate the Creature are a blind man and the nurse-explorer Walton, who first encounters the Creature through Victor's words.

Lennard Davis posits that in modernity a statistical understanding of normalcy-looking like a majority of other people - replaced the normality of the Greeks, who saw it as resemblance to an abstract and idealized standard (Davis 2017, 2). Because modern "normalcy" in appearance and/or function is a social category, patients are usually in agreement with their physicians concerning its value. Even Frankenstein's Creature "admire[s] perfect forms, $[\ldots]$ their grace, beauty, and delicate complexions" (90). The underlying norms are a conservative value, paralleling the tidy restitution story that physicians and patients pursue along with an ideal of resemblance/belonging. It is beyond the scope of this paper to debate the issues of power, dominance, and control that underlie this desire, but right or wrong, it often is incompletely fulfilled. Dying, of course, represents the most extreme outcome of a "failure" to ward off the difference from life that death embodies. But often, even when the patient survives, they survive in a less "beautiful" state - whether because they bear external scars, physical aberrations or distortions; or because while appearing once again "similar" to others, in fact they carry forward significant limitations in terms of stamina, function, pain, and even outlook.

Such limitations, and the hidden identity they betoken, help to answer the question of why difference is so threatening in the clinical context, even as it clearly demarcates self from other. It may be precisely the similarities rooted in difference, the persistence of resemblance, and the close proximity in us all to deterioration, decline, and death, that cause panic, silence, and, at best, "speaking past." Perhaps it is less difference than a similarity, the "mirroring" within difference (Diedrich 2018) that doctors (and society as a whole) find disconcerting and frightening. The sick are both like and not like the well, both like and not like the doctor who attempts to restore them to health. The sick foreshadow our eventual end, even as we see ourselves in them. 
Here lies a challenge to the apparent divide between the sick and the well in Frankenstein. Though the Creature looks jaundiced, palsied, and infected, he exhibits unflagging physical stamina, speed and strength. Victor is another story. "Every night I was possessed by a slow fever," he says of his early days of work on the Creature, "a disease" (38). He takes to his bed again and again, wastes away altogether in the end. His plight makes us think of burned-out physicians who suffer a variety of symptoms and too often seek refuge in suicide (West and Dyrbye 2018). Yet it is the Creature who, at the end of the novel, expresses an active desire for death. Perhaps it is in invisible particulars (they are lonely, they long for love, they suffer, they are vulnerable and mortal) that Victor and the Creature are most similar. Their interactionlike ours with them - suggests that it is this very similarity as it works with the absence of other superficial similarities (of education, social class, health status, and so on) that potentially drives the physician's flight and the patient's desperation alike.

Still, it is the aesthetic ideals that hog our attention and gobble up our desires. To acknowledge in language shared by doctor and patient the prevalence of such ultimately abstract notions and their sociocultural origins and motives might be a first step toward freedom from them, paving the way to recognition that these abstractions are unlikely to be fully realized at the individual level. What is more, to the extent that aesthetic priorities of form and function are not objective but born of the social medium of language, they belong to both physicians and their patients. Discussion of these priorities reveals our ideals' intersubjective quality and the social scripts that reinforce them. In turn, such discussion opens the possibility of transforming those priorities into goals that acknowledge and if possible honor the patient's new and not yet known - possibly unknowable — reality, their new story, as yet in the making. For example, beauty itself might be redefined in the shadowy space that the Creature inhabits - just outside the comforting fences of category, criteria, norm, and standard. Perhaps speaking with patients can restore not necessarily their "normalcy," but the inclusion the Creature craves. Perhaps, as the palliative care movement in medicine has emphasized (Sinclair et al. 2017), decline and eventual death can be realities of living that can be recognized and integrated in a model of intimate and sustained care.

Physicians who open themselves to such perhapses can become collaborators and cocreators, working with patients (and with the patients in themselves) to accept and even embrace the uncertain, open-ended transformations that disease mobilizes. In looking at the sick, the doctor, taking into consideration what can't be seen-their suffering, their endurance - may feel admiring and humbled or threatened and inferior. A position of alliance within difference and of difference within alliance - best expressed in the now imaginatively informed act of speaking with the patient - may move the physician closer to admiration and humility. Foreclosing this possibility ensures the sense of threat and inferiority.

\section{What emotions arise when expectations and ideals are violated?}

As we have noted, sometimes - indeed more often than anyone likes to acknowledge"recreation" falls short of the physician's (and patient's) expectations, or even goes awry. After medical intervention, the "recreated" patient (altered by treatment) still has cancer, cannot control their diabetes. Retracing Shelley's own plot, and the interactions that advance or retard it, we have shown how the physician might well be "horrified" (disappointed, ashamed) and flee (emotionally abandon the patient and their less-than-perfect outcome). Speaking with Frankenstein helps bring festering feelings to light in both doctor and patient. 
In so doing, it helps us imagine remedies for the ills those possibly unavoidable feelings breed (Shapiro 2013).

Here we might return to the Creature's oft-remarked hideousness. The word "hideous"which Shelley herself adopted to describe her novel ("hideous progeny")-connotes both shame (hiding) and fear (the word's origins seem to lie in an Old French word meaning just that). Loathing, fear, and disgust also abound. None of these emotions has been formally incorporated into the script of physician/patient relationships. Their omission makes it difficult to imagine the alternative emotional responses that might paradoxically grow out of them. It is notable as well that several of the feelings floated in Frankenstein are experienced by both Victor and his Creature. This commonality is striking, since it shifts affect from a place within an individual to the space between individuals. Like Frankenstein's creature himself, emotions are always on the move in Frankenstein. This mobility alone can tell us something about the role that feelings play within the clinical relationship shadowed in its pages.

Take disgust. When Victor sees his Creature come to life, "breathless horror and disgust filled my heart" (39). Victor's response to what another might have seen as a success expresses the uniquely visceral quality of disgust (literally "tasting against") itself. Evolutionary biology frames disgust as a sensational and interpretive adaptation to the physical environment, its function to protect the physical life of both individuals and the social body. Hence, for instance, putrid meat disgusts simply because it makes us physically ill; disgust keeps this threat from breaching the barrier of the body and in so doing reaffirms the solidity of that barrier. As Martha C. Nussbaum proposes in the legal context, disgust also seems to protect the category of humanity by excluding some others from it (Nussbaum 2004, 4). From this point of view, a physician's disgust, although rarely named, is predictable and can even work psychologically to minimize any disturbing likeness to the unsavory patient (Faulkner 2013; Feder 2011). Disgust itself all too often can generalize from the disease to the patient herself, especially when she is not able to fully recover — and thus distance herself - from the disease.

Just so, Frankenstein's creature internalizes Victor's disgust, turning against his own body. Glimpsing himself in a "transparent pool," he becomes "convinced In the very fibers of his body that "I was in reality the monster that I am." He is consequently "filled with the bitterest sensations of despondence and mortification" (90). Culminating in the shame that literally connotes social death ("mortification"), the self-recognizing monster's bodily "sensations" are inseparable from culturally scripted emotional routines (Kavey and Friedman 2018). Frankenstein here speaks to present-day medical care, where the same revulsion can arise, albeit unconsciously, in the physician and be reflected in the patient.

Victor experiences fear as well as disgust. What is its object? Is it simply the Creature's hideous body? Victor's own loss of control over what he has created? The possibility that he is more like the Creature than different? Why might a physician also fear even a recovering patient? It is useful to keep in mind that medical treatment itself is highly ritualized, and one of its unspoken aims is to ward off fear of failure, fear of contamination, and fear of death (Loewy 1986; Lawton et al. 2020; Winkel et al. 2019). This apotropaic function often breaks down under the pressure of experience, exposing the fragility of technological and practical measures that have been taken to deflect these fears. Even more to be feared is the moment when these measures and the medical practices that affect them might themselves break down.

Such potential collapse seems to violate a psychological or at least characterological profile. Physicians are often by nature "doers," trained to "help" people, to intervene actively and make a positive difference for others (Remen 1998). They are not armchair philosophers. Unlike Victor, they are trained to keep their fantasies to themselves. So situations in which they are helpless, 
when they cannot effect positive change, can easily engender fear. To guard against that fear, they must continue to believe in the power of their treatments and interventions. In the magical syllogism that results, failure must either not exist or if it does it is the patient who is responsible (Ruberton et al. 2016). From this it follows that it will always be the Creature who is inadequate.

Patients too can be consumed by fear and are indeed more readily permitted these fears, whose objects include the unknown, possible recurrence of disease, potential pain as well as social isolation, and exclusion from a familiar orienting social context that also confirms personal identity. While Frankenstein's Creature strikes us as fearsome and fearless-he undeniably menaces, tricks, and murders his way through the last part of his personal story - these fears also stalk him. They represent the other side of the anger that turns him into a serial murderer and arsonist. The Creature's mid-novel conversation with Victor takes us behind the crimes to the possible sources of that anger. The Creature asks Victor-and us - to imagine that his anger develops out of experience, the result of rejection by the society with which the Creature nonetheless identifies. While that society, as a society, refuses to accept him as familiar, the Creature's anger can also be seen as a response to his own insertion, without anyone to help or guide him, into an unfamiliar and alien life. It is a response to what he does not know. In turn - and in kind - he asks us, and Victor, to draw on what we do not know (fear's foundation) in order to understand it.

As a rule, patients do not literally become murderers or arsonists. Still, marginalization by society, and emotional abandonment by physicians after they have received any "fixing" often ignites anger. A patient, altered by illness, often finds it difficult to reintegrate into society. Her family and friends perceive her differently and treat her differently. She becomes defined by her "difference." Although the patient is not a child, she is reborn into a world that no longer makes complete sense to her and that she no longer understands as she did prior to sickness. This process is mirrored, if inexactly, in the Creature's stumbling efforts to learn the rules of a world new to him. Rage engulfs the Creature not in the face of the difficulty of these rules but at their frightening refusal to represent or accommodate his anomalous nature.

Doctors too can experience anger (Anderson et al. 2016), which they often minimize as "frustration." Hence anger is externalized in language that blames the patient for her disease: "The patient has failed treatment protocol"; "Patient left against medical advice;" "Patient is noncompliant." Less commonly, anger can be directed inward-i.e., anger at one's own shortcomings, limitations, and imperfections as a physician. Anger by definition functions to separate those who feel it from what they feel it to be about. But when anger is verbally expressed in the second person as opposed to mutely enacted in the first or third, a seeming gulf begins to shrink. Anger too is a self-protective mechanism.

Finally, both the Creature and Victor succumb to "despondence." The Creature internalizes society's perspective on his body; "convinced that I was in reality the monster that I am," he is soon "filled with the bitterest sensations of despondence and mortification" (90). Hence his final words articulate only his desire for death: once, he poignantly remembers, "I should have wept to die; now it is my only consolation. [...W]here can I find rest but in death?" (190). Because the Creature never actually dies, this remains, significantly, an open question. Depression's source seems to lie not in remorse for his crimes but rather in the experience of ultimate abandonment by Victor, who has just given up the ghost. The Creature's despair and desire for death - his commitment to negation - thus paradoxically asserts a commonality. Somewhat similarly, if a patient has been returned to a life that no longer recognizes her and does not honor the ways in which she has changed as a result of her experience of illness, she may become despondent and depressed. If she feels abandoned by her doctor and 
misunderstood by her social network, it may be difficult to reconnect with life. Speaking with Frankenstein lets us glimpse the causes and even logic of what seem to be irrational negative reactions when life is restored or recreated in a new form. This is also a loss, an experience of absence and invisibility.

By opening a conversation with that experience as it shapes Shelley's novel, we can begin to speak about the nuanced range of emotions that can arise between physicians and their patients. This is because the novel itself does not simply represent those emotions; they are all spoken of by those who feel them, and who are often unaware of their full scope. Thus for example while the Creature variously expresses anger, self-loathing, and despair, his story of such expressions, as told to Victor, then to Walton, and ultimately to us, also means that the Creature offers a vocabulary, even a syntax and grammar, for otherwise inarticulable, antisocial feelings. Hence in their very obscurity those feelings become visible and therefore social. We are prompted to think that a patient's own voice might have its own vocabulary, syntax and grammar. These might remain vague, obscure, and not easily graspable by the physician. But - not unlike the sublime of eighteenth-century aesthetics, which shares these qualities - a patient's language and the antisocial feelings that fracture it might still be, in every sense, regarded.

The possibility that a patient's voice might become accessible in and through its refusal of conformity waxes when specific emotions are no longer seen as the property of either patient or physician but instead as the dynamic contents of a shared repertoire. (Weilenmann et al. 2018). This commonality points to what Brennan, Teresa memorably terms the "transmission of affect," rooted in affect's deeply participatory nature, the sense in which feelings are by definition shared, arising situationally to become the common currency of those who feel them $(2004,3)$. "Speaking with" potentially both acknowledges and interprets physician affect by binding it to the affective responses of the patient. Seemingly reactive emotions prove not only mimetic but ultimately intersubjective. What is more, they may themselves originate in social norms as much as in bodily experiences, thereby reminding us that the experience of being brought (back) to life takes place in both registers, and indeed at the vanishing point where they intersect.

This expanded framework lets us imagine alternatives to anger, disgust, shame, and despair without denying their validity. What, for example, of laughter? Given Frankenstein's absurd plot, its missing sense of humor can come as a surprise. The "grin" that wrinkles the Creature's cheeks in his first attempt to communicate with Victor gestures toward this alternative and makes us wonder if it is not actualized because humor requires the shared frame of reference that Victor denies the Creature. Alternatively, we might remember that, linguistically speaking, next to "affect" lies "affection." Affection is actually the first feeling we encounter in Shelley's novel, expressed in Walton's opening paragraph to his absent sister and developed in his caregiving relationship to Victor. "Affection" comes from a Latin word for influence, sharing a root with "affect" and "effect." At once organic and intersubjective, affection is born through the creative exchange of language on the basis of not knowing and itself bears new possibilities for care. Those possibilities include accessing a patient's voice not just by encouraging them to speak expressively in the first-person ("I am in pain") but by counting mysterious, initially undecipherable speech, or even non-speech as communication in its own right. 


\section{What are the physician's responsibilities to the patient?}

Such possibilities, at present, unfortunately must include abandonment. Both in medicine and outside it, there is an ethical commitment to non-abandonment in relation to those toward whom we have incurred an obligation, duty, or relationship (Pellegrino 1995). Victor, as we have seen, refuses to respond to the still needy creature he has brought to life (Belling 2018). In fact, he actively flees it, overwhelmed with horror at this rebuke to his own efficacy and ultimately to his own autonomy. Victor will never name his monster, and he acknowledges no emotional obligation to him. Further, Victor allows others to take the blame for both his own crimes and those of the Creature. While Victor does come to feel guilty about the latter, he never assumes responsibility for them. Indeed, he is able to see his implication in the murders the Creature commits perhaps only because they mirror his own actions in their crude inversion of bringing-to-life.

Modern-day physicians too may abandon their patients, occasionally literally, but more often emotionally (Derksen et al. 2017; Wollny et al. 2018; Stuart et al. 2019). The patient seeks compassion, caring, and most of all recognition ("see me and hear me") from their physician (and society); but instead receives opprobrium and banishment ("I can't help you any longer"). Working our way imaginatively into Victor's point of view lets us explore both the causes and the consequences of these responses. We can then ask what forms responsibility may take, and imagine how a physician might be better able to assume some degree of ethical responsibility toward the patient.

Victor fails to prepare his Creature to enter the world, thereby guaranteeing difficulty of reentry and the enhancement of stigma in the patient role. Leaving the Creature to his own devices, he also fails to acknowledge the larger implications of the malady that he thereby enhances, and the place both he and the Creature have within a larger social history. Victor's failure leads us to wonder how helpful it might be, in returning to life, if patients saw physicians as allies helping them to navigate difference and softening the thoughtless judgments of the larger society. Speaking with Victor's failure helps us imagine physicians who, instead of mirroring societal fears of decay and death, find the courage to stand with the patients they have helped to birth into a new life story.

Meanwhile, speaking with Frankenstein itself helps us envision medical ethics as an unfolding series of responses to arising contingencies in which choices are complicated and suffering is inevitable. Here blame - so rigorously regulated and codified in malpractice lawtakes on a new cast. Victor blames his creation for the horrors that follow from its arrival at life. Victor then blames himself for having created the Creature, thereby again asserting his power as Creator, however flawed. But Victor does not hold himself accountable for the subsequent neglect that the Creature identifies as the source of his own obvious ethical shortcomings. Nor does Victor fault himself for telling no one what he has done, or for his own withdrawal from a circle of friends and family. Yet in this he may be far more culpable than he is for the heroic act of life-giving gone awry. At the very least, we sense in Victor's evasion of responsibility new openings to speak about the ethical relationship between physicians and patients.

The physician who blames her patient for the limitations of aesthetic and functional outcomes and for the difficult emotions that arise in care is also protecting the myth of her own efficacy. And although much progress has been made in terms of honestly acknowledging physician error (Hilfiker 1984; Helo and Moulton 2017), there is still a tendency to base error on outcome, and to maintain silence, as did Victor, unless the consequences make speaking out 
unavoidable. If "outcome" itself is more broadly defined, as a possibility inherent in every moment instead of as a measurable consequence, other options and a deeper well-being might emerge.

What happens when we, Shelley's present-day readers, share the responsibility of interpretation that is itself historically part of the physician's job? Different readers might place responsibility differently. One might find that patients may not in fact be within their rights to ask for further care and attention, especially from representatives of a healthcare system which ethically cannot supply it. This confrontation with the limits of medicine might constitute a kind of morally acceptable "vanishing" on the part of the physician, different from abandonment because the speaking-with-the-patient component of the relationship never disappears, although aggressive treatment might. Another reader might note that, for all the Creature's desire to be heard and seen, in the end, he wants only to disappear. Indeed, that is exactly what he does, vanishing into the "darkness and distance" of the novel's last sentence (191). When patients do not wish to speak, when they choose to retreat or otherwise opt out of conversation, they are not not speaking; rather they have chosen silence as their voice. We thus might see in the Creature's retreat into the unknown wilds as pursuit of death with dignity (Allmark 2002), after enduring as much suffering as he could bear.

Or what if Victor were the kind of physician that he ideally could be, the linguistic medium that he shares with his unnamed creation developed to its fullest capacity? The Creature might then choose not disappearance but rather re-emergence into a world that his presence would transform. As it is, at the end of Shelley's novel the Creature is "borne away on the waves, and vanish[es] in darkness and distance" (191). To one reader, such waves might bring to mind the waves of sound that carry words, such that the patient remains perceptible even in their disappearance. To another it might be significant that it is the nurse, Walton, and not Victor, who witnesses and articulates this paradox, reminding us that an ethics of caring and speakingwith is by no means the exclusive province of physicians, and in fact has been developed most fully and profoundly in the nursing literature (Lachman 2012). Walton's open-ended acceptance of a mystery reminds us that "speaking with" is in itself a source of life. At least potentially.

In embracing this potentiality, "we," the authors of this article, understand that the greater "we" that appears in its pages is likely to include more physicians than patients. The question of just how and where that "we" might access a patient's voice is one that we, the authors, deliberately leave open, even as we have primarily imagined this to be in literal, spoken conversations that are themselves informed not just by empathy but by a chastened imagination. In the wake of pandemic and its enforced isolation, the rapid, almost Frankensteinian, evolution of digitally-based consultations confirms the folly of supposing at any given moment that we know all the possible sites of exchange between physicians and patients. But that same evolution also confirms the value of supposing itself — of conceiving, of imagining, of literally substituting or 'putting under'-in the positive transformation of care.

\section{References}

Allmark, Peter. 2002. "Death with Dignity." Journal of Medical Ethics 28 (4): 255-257.

Anderson, Patricia F., Elise Wescom, and Ruth C. Carlos. 2016. "Difficult Doctors, Difficult Patients: Building Empathy." Journal of the American College of Radiology 13 (12): 1590-1598.

Appiah, Anthony. 2017. As If: Idealization and Ideals. Cambridge, MA: Harvard University Press. 
Belling C. 2018. "Foreword: A Year of Frankenstein.” Literature and Medicine 36 (2): 261-263.

Bradshaw, Michael. 2019. “'Its Own Concentred Recompense': The Impact of Critical Disability Studies on Romanticism." Humanities 8 (2): 103.

Brennan Teresa. 2004. The Transmission of Affect. Ithaca: Cornell University Press.

Charon, Rita. 2006. Narrative Medicine: Honoring the Stories of Illness. Oxford: Oxford University Press.

Charon, Rita, Nellie Hermann, and Michael J. Devlin. 2016. "Close Reading and Creative Writing in Clinical Education: Teaching Attention, Representation, and Affiliation." Academic Medicine 91 (3): 345-350.

Codr, Dwight. 2014. "Arresting Monstrosity: Polio, Frankenstein, and the Horror Film.” PMLA 129: 171-187.

Davis, Lennard J. 2017. "Disability, Normality and Power.” The Disability Studies Reader, edited by Lennard J. Davis, 1-16. New York: Routledge.

Derksen, Frans, Tim C. Olde Hartman, Annelies van Dijk, Annette Plouvier, Jozien Bensing, and Antoine LagroJanssen. 2017. "Consequences of the Presence and Absence of Empathy During Consultations in Primary Care: A Focus Group Study with Patients." Patient Education and Counseling 100 (5): 987-993.

Diedrich, Lisa. 2018. "Being-Becoming-Monster: Mirrors and Mirroring in Graphic Frankenstein Narratives." Literature and Medicine 36 (2): 388-411.

Faulkner, Joanne. 2013. "Disgust, Purity, and a Longing for Companionship: Dialectics of Affect in Nietzsche's Imagined Community." Journal of Nietzsche Studies 44 (1): 49-68.

Feder, Ellen K. 2011. "Tilting the Ethical Lens: Shame, Disgust, and the Body in Question.” Hypatia 26 (3): 632 650.

Foucault, Michel. [1973] 1994. The Birth of the Clinic: An Archaeology of Medical Perception NewYork: Vintage.

Frank, Arthur W. 2000. "Illness and Autobiographical Work: Dialogue as Narrative Destabilization." Qualitative Sociology 23 (1): 135-156.

. 2013. The Wounded Storyteller: Body, Illness, and Ethics, Second Edition. Chicago, Illinois: University of Chicago Press.

Helo, Sevann, and Carol-Anne E. Moulton. 2017. "Complications: Acknowledging, Managing, And Coping with Human Error.” Translational Andrology and Urology 6 (4): 773-782.

Hilfiker, David. 1984. "Facing our Mistakes." New England Journal of Medicine 310:118-122.

Stoddard Holmes, Martha. 2018. "Born This Way: Reading Frankenstein with Disability."Literature and Medicine 36 (2): 372-387.

Johnson, Jeffrey. 2018. "Dr. Frankenstein, I Presume? Revising the Popular Image of Frankenstein." Literature and Medicine 36:287-311.

Kavey, Allison B. and Lester D. Friedman. 2018. "Introduction: Chemistry, Disability, and Frankenstein." Literature and Medicine 36 (2):264-268.

Lachman, Vicki D. 2012. “Applying the Ethics of Care to Your Nursing Practice.” Medsurg Nursing 21 (2): 112.

Lawton, Andrew J., Christopher W. Lawton, Sarah Scott B. Dietz, Erin E. Stevens, and Jo M. Weis. 2020. "Exploring and Managing the Impostor Phenomenon in Palliative Care: A Case Series." Journal of Palliative Medicine 23(4): 586-590.

Locock, Louise, and Sue Ziebland. 2015. "Mike Bury: Biographical Disruption and Long-Term And Other Health Conditions." In The Palgrave Handbook of Social Theory in Health, Illness and Medicine, edited by F. Collyer, 582-598. London: Palgrave Macmillan.

Loewy, Erich H. 1986. "Duties, Fears and Physicians." Social Science \& Medicine 22 (12): 1363-1366.

Macnaughton, Jane. 2015. “"Elegant' Surgery: The Beauty of Clinical Expertise.” In The Recovery of Beauty: Arts, Culture, Medicine, edited by Jane Macnaughton, 175-198. Palgrave Macmillan, London.

Morris, David B. 2001. "Narrative, Ethics, and Pain: Thinking with Stories." Narrative 9 (11): 55-77.

Nassir, Ghaemi. 2008. "God Syndrome: Why Do Doctors Think They Are God?" Psychology Today. https://www.psychologytoday.com/us/blog/mood-swings/200810/godsyndrome .

Nussbaum, Martha C. 2004. Hiding from Humanity: Disgust, Shame, and the Law. Princeton: Princeton University Press.

Pellegrino, Edmund D. 1995. "Nonabandonment: An old Obligation Revisited.” Annals of Internal Medicine 122 (5): $377-378$.

Quick, Jonathan D., and Bronwyn Fryer. 2018. "The Triple Threat: Bioterror, Bio-Error, and Dr. Frankenstein." In The End of Epidemics: The Looming Threat to Humanity and How toStop It, edited by Jonathan D. Quick and Bronwyn Fryer, 57-77. New York: St. Martin's Press.

Remen, Rachel Naomi. 1998. "In the Service of Life.” Meridians-Columbia 5:15-16.

Rollin, Bernard. 2004. "Biotechnology and Animals: Ethical Issues in Genetic Engineering and Cloning." In A Companion to Genethics, edited by J. Burley and J. Harris, 70-81. Blackwell Publishing Ltd, Oxford.

Ruberton, Peter M., Ho P. Huynh, Tricia A. Miller, Elliott Kruse, Joseph Chancellor, and Sonj Lyubomirsky. 2016. "The Relationship between Physician Humility, Physician-patient Communication, and Patient Health." Patient Education and Counseling 99 (7): 1138- 1145. 
Savulescu, Julian, and John Harris. 2004. "The Creation Lottery: Final Lessons from Natural Reproduction: Why Those who Accept Natural Reproduction should Accept Cloning and other Frankenstein Reproductive Technologies." Cambridge Quarterly of Healthcare Ethics 13 (1): 90-95.

Shapiro, Johanna. 2013. "The Feeling Physician: Educating the Emotions in Medical Training." European Journal for Person Centered Healthcare 1 (2): 310-316.

Shelley, Mary. [1818] 1993. Frankenstein; or, The Modern Prometheus. Edited by Marilyn Butler. Oxford; Oxford University Press.

Sinclair, Shane, Kate Beamer, Thomas F. Hack, Susan McClement, Shelley Raffin Bouchal, Harvey M. Chochinov, and Neil A. Hagen. 2017. "Sympathy, Empathy, and Compassion: A Grounded Theory Study of Palliative Care Patients' Understandings, Experiences, and Preferences.” Palliative Medicine 31 (5): 437-447.

Sontag, Susan. 1977. Illness as Metaphor and AIDS and Its Metaphors. New York: Picador.

Stuart, Brad, Tracey Danaher, Rana Awdish, and Leonard Berry. 2019. "Finding Hope and Healing When Cure Is Not Possible." Mayo Clinic Proceedings 94 (4): 677-685.

Wade, Derick T., and Peter W. Halligan. 2017. "The Biopsychosocial Model of Illness: A Model Whose Time Has Come.” Clinical Rehabilitation 31 (8): 995-1004.

Webster, Annie. 2018. "Ahmed Saadawi's Frankenstein in Baghdad: A Tale of Biomedical Salvation?" Literature and Medicine 36 (2): 439-463.

Weilenmann, Sonja, Ulrich Schnyder, Brian Parkinson, Claudio Corda, Roland Von Kaenel, and Monique C. Pfaltz. 2018. "Emotion Transfer, Emotion Regulation, and Empathy-Related Processes in Physician-Patient Interactions and Their Association with Physician Well-Being: A Theoretical Model." Frontiers in Psychiatry 9:389.

West, Colin P., Liselotte N. Dyrbye, and Tait D Shanafelt. 2018. "Physician Burnout: Contributors, Consequences and Solutions.” Journal of Internal Medicine 283 (6): 516-529.

Williams, Simon. 2000. "Chronic Illness as Biographical Disruption or Biographical Disruption As Chronic Illness? Reflections on a Core Concept." Sociology of Health and Illness 22 (1): 40-67.

Winkel, Abigail F., Annie Robinson, Aubrie-Ann Jones, and Allison P. Squires. 2019. "Physician Resilience: A Grounded Theory Study of Obstetrics and Gynaecology Residents." Medical Education 53 (2): 184-194.

Wollny, Anja, Michael Pentzek, Oliver Rudolf Herber, Heinz-Harald Abholz, Andrea Icks, Stefan Wilm, and Elisabeth Gummersbach. 2018. “General Practitioners' Attitudes Towards Patients with Poorly Controlled Type 2 Diabetes: A Qualitative Study.” BMC Family Practice 19 (1): 49.

Publisher's Note Springer Nature remains neutral with regard to jurisdictional claims in published maps and institutional affiliations. 